NEWS

\title{
Demand for malaria drug soars
}

Farmers and scientists struggle to keep up with needs of ambitious medicine-subsidy programme.

From bust to boom to bust again: artemisinin, the key ingredient of front-line antimalarial drugs, is entering the third chapter of its turbulent history. A decade ago, the compound available only from the sweet wormwood plant Artemisia annua - was scarce and expensive. But by 2007 , the market was wallowing in a surfeit of the drug as farmers flocked to grow the crop. Now, as a US\$343-million initiative starts to battle malaria through hugely subsidized medicines, suppliers are again worried that there will not be enough artemisinin to go around, while farmers, plant breeders and synthetic biologists are hoping that they can snap the drug out of its roller-coaster supply cycle.

This year's problems began with what should be a malaria success story. The Global Fund to Fight AIDS, Tuberculosis and Malaria last month saw its first orders for cheap drugs under its Affordable Medicines Facility - Malaria (AMFm) initiative. Using subsidies, it plans to cut the price of artemisinin-based combination therapies (ACTs), which partner artemisinin with another drug to reduce the chance of malaria parasites developing resistance, as they have done to treatments such as chloroquine.

\section{Costly convenience}

Governmental public-health clinics already offer ACTs at just $\$ 1$ per dose, but roughly $60 \%$ of patients with malaria opt for convenience and buy the drugs from local market stalls and private pharmacies - even though they cost many times more. The AMFm initiative, running as a two-year trial in seven African countries and in Cambodia, hopes to ensure that even the private sector will sell ACTs at \$0.20-0.50 per dose. That should improve access to the drugs, and may stop patients buying cheap but ineffective chloroquine or the single artemisinin therapies that are promoting resistance. It will also drive up demand for artemisinin.

Artemisinin suppliers have seen this all before. In 2005, the World Health Organization declared that much more of the drug was needed to increase the production of ACTs. At the time, researchers led by Jay Keasling at the University of California, Berkeley, thought that synthetic biology could solve the supply problem. They hoped to modify the genomes of bacteria

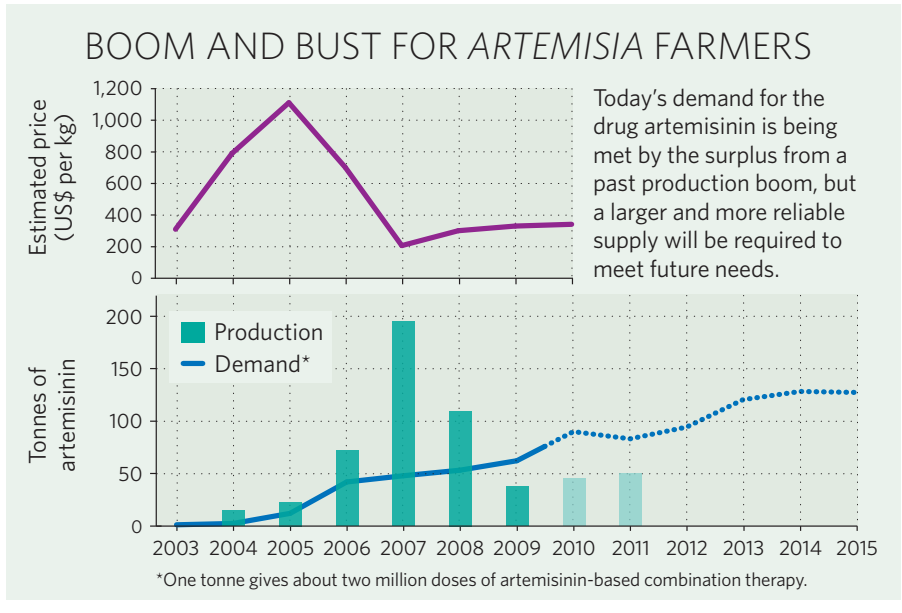

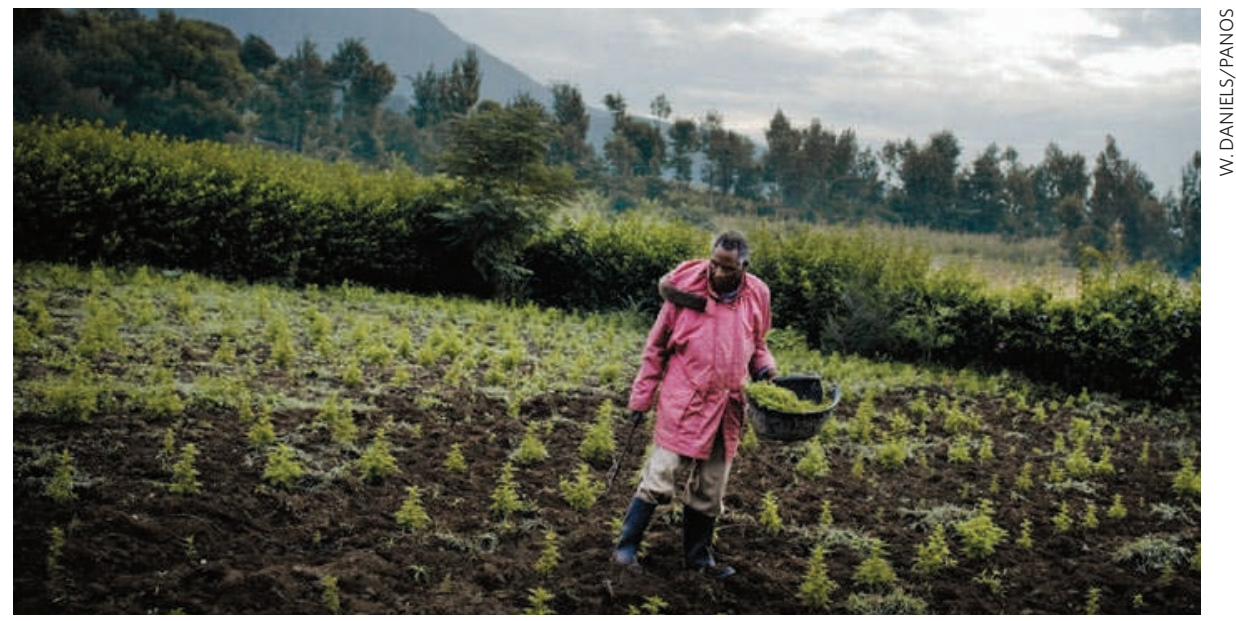

Hybrid plants could boost artemisinin supplies from farms in Tanzania (above) and elsewhere.

and yeast to produce a precursor of artemisinin. Fermenting the organisms in huge vats could yield a plentiful and inexpensive drug supply.

Keasling's semi-synthetic artemisinin project received $\$ 42.6$ million over five years from the Bill \& Melinda Gates Foundation, and became a focus for biotech firm Amyris of Emeryville, California, which spun out from Keasling's lab. It successfully added or tweaked a dozen genes in yeast to make artemisinic acid (D.-K. Ro et al. Nature 440, 940-943; 2006), and gave a royalty-free licence to drug firm Sanofi-aventis, headquartered in Paris, to make semi-synthetic artemisinin on a commercial scale. Four years on, the product is still two years away, says the drug company, which is scaling up production to 100,000 -litre vats, financed by another $\$ 10.7$-million grant from the Gates foundation, and with assistance from the Institute for OneWorld Health, a non-profit organization in San Francisco, California.

While this technology was being developed, farmers in China and Vietnam planted tens of thousands of hectares of Artemisia, and by 2007 the market was swamped. The price of artemisinin plummeted from more than $\$ 1,100$ per kilogram to around $\$ 200$ per kilogram (see 'Boom and bust for Artemisia farmers'), putting some 80 processing companies - and untold numbers of farmers - out of business.

Even though artemisinin was being sold cheaply (compared with the price that Sanofiaventis will set in 2012), millions of people in sub-Saharan Africa were still not getting access to the ACTs. "We havelearned there is a lot more to it than cost," says Jack Newman, co-founder and senior vice-president for research at Amyris. Improving access to the medicines is as important as driving down their price - hence the idea for the AMFm, and its focus on the local businesses that sell treatments.

If farmers grew enough Artemisia before, why not again? With food prices rising, the incentive to plant the crop this time is low, notes Malcolm Cutler, an artemisinin-industry expert and director of the consultancy FSC Development Services, near Gloucester, UK. His priority is to improve communication between growers, processors and drug companies, and to help farmers who must decide to plant Artemisia 14 months before that 
crop's drug will be produced.

This year, the Assured Artemisinin Supply System (A2S2) initiative, supported by the international drug-purchasing facility UNITAID, began to give advance loans to the companies that extract artemisinin from plants, and to encourage drug firms to sign long-term contracts with them. About 10,000 hectares of Artemisia was planted this year, twice as much as in 2009. But recent floods in China and Vietnam, and a drought in East Africa, mean that yields of artemisinin for use in 2011 may be only two-thirds of what has been planted, says Cutler.

\section{Breeding boost}

Yields could be vastly improved by planting new Artemisia strains. On average, one kilogram of its dried leaves yields some 8 grams of artemisinin. But at the National Institute of Agricultural Botany in Cambridge, UK, researchers have used selective breeding to create hybrid plants that produce up to 24 grams, says Colin Hill, chair of an Artemisia breeding consortium supported by the UK Department for the Environment, Food and Rural Affairs. These plants are now being grown and harvested commercially in Madagascar, and trialled in South Africa, Uganda, Zimbabwe and the United States, as well as in Britain.

In an alternative approach, Ian Graham and colleagues at the University of York, UK, identified key Artemisia genes that could optimize agricultural yields, robustness or other desirable traits when the plant is grown in different areas of the globe (I. A. Graham et al. Science 327, 328-331; 2010). Graham says that the work has helped to create plants that produce up to $50 \%$ more artemisinin per kilogram of leaves than the best commercial variety. They expect to release seed to commercial growers in mid-2012.

Despite the advances in plant biotechnology, Keasling says that semi-synthetic artemisinin is still sorely needed. Although it began as a way to make the drug more cheaply, the mass-produced semi-synthetic will be no cheaper than the plant-derived version - partly because Sanofi-aventis does not want to undercut farmers. Instead, it will be used to smooth out the cycle of boom and bust in crop-based artemisinin supply. "A stable and adequate source of artemisinin would be fundamentally important," says Silvia Schwarte of the World Health Organization's malaria programme.

As Newman says: "If you suddenly need twice as much artemisinin, you just fire up another fermenter."

Richard Van Noorden

\section{Sponge genome goes deep}

With a simple body plan lacking organs, muscles and nerve cells, the sea sponge hardly seems a rich avenue for study. Yet this humble organism squats firmly at the doorway to one of life's great mysteries: the leap to multicellularity.

Telltale molecular fragments teased out of ancient sediment ${ }^{1}$ show that sponges existed some 635 million years ago - the oldest evidence for metazoans (multicellular animals) on Earth. Now, a draft genome sequence of the Great Barrier Reef demosponge (Amphimedon queenslandica), published in this issue ${ }^{2}$ (see page 720 ), offers a comprehensive look at the genetic mechanisms that first allowed individual cells to work together as parts of a larger whole. As an added benefit, this genome may shed light on how primitive animal cells first learned to cope with the enduring hazard of collective existence: cancer.

"As the earliest branching lineage from our last common ancestor, sponges can tell us a lot about what is needed to make an animal," says geneticist Mansi Srivastava, the paper's lead author, now a postdoc at the Massachusetts Institute of Technology in Cambridge.

With more than 18,000 individual genes, the sponge genome represents a diverse toolkit, coding for many processes that lay the foundations for more complex creatures. These include mechanisms for telling cells how to adhere to one another, grow in an organized fashion and recognize interlopers. The genome also includes analogues of genes that, in organisms with a neuromuscular system, code for muscle tissue and neurons.

According to Douglas Erwin, a palaeobiologist at the Smithsonian Institution in Washington DC, such complexity indicates that sponges must have descended from a more advanced ancestor than previously suspected. "This flies in the face of what we think of early metazoan evolution," says Erwin.

Charles Marshall, director of the University of California Museum of Paleontology in Berkeley, agrees. "It means there was an elaborate machinery in place that already had some function," he says. "What I want to know now is what were all these genes doing prior to the advent of sponge."

The analyses of Srivastava and her colleagues suggest that there was a crucial window, some 150 to 200 million years in duration, when the basics of multicellular life emerged. Nearly one-third of the genetic alterations that distinguish humans from their last common ancestor with singlecelled organisms took place during this period. These changes would have occurred within our sponge-like forebears.

The researchers also identified parts of the genome devoted to suppressing individual cells that multiply at the expense of the collective. The presence of such genes indicates that the battle to stop rogue cells - in other words, cancer - is as old as multicellularity itself. Such a link was recently hinted at by work showing that certain 'founder genes' that are associated

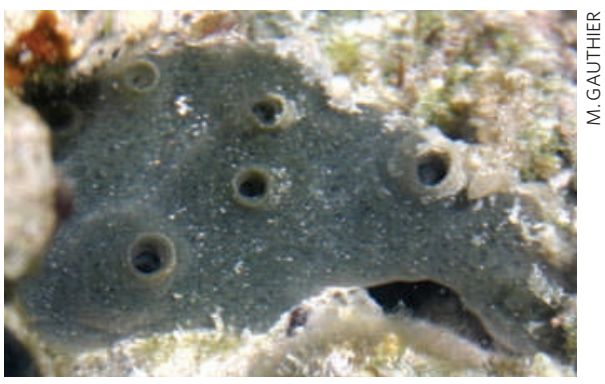

The genome of the demosponge $A$. queenslandica offers a glimpse at the dawn of multicellular life.

with human cancers first arose at about the same time as metazoans appeared ${ }^{3}$. The demosponge genome shows that genes for cell suicide - those activated within an individual cell when something goes wrong - evolved before pathways that are activated by adjacent cells to dispatch a cancerous neighbour.

"Cell suicide predated cell homicide," says Carlo Maley, an oncologist at the Wistar Institute in Philadelphia, Pennsylvania. This suggests that the single-celled colonial organisms that gave rise to our ancestors had already evolved mechanisms to kill themselves, which multicellular creatures later exploited as a cancer defence.

"Cancer was not the original motivation for this work," says Srivastava. "But now we can learn about the ways in which multicellular animals have to regulate themselves and the original function of these genes."

Adam Mann

1. Love, G. D. et al. Nature $457,718-721$ (2009)

2. Srivastava, M. et al. Nature 466, 720-726 (2010)

3. Domazet-Lošo, T. \& Tautz, D. BMC Biol. 8, 66 (2010). 